\title{
RARE CASE OF ULNAR SESAMOID FRACTURE OF THE THUMB: A CASE REPORT
}

\author{
Roshan Pais ${ }^{1}$, Maruthi C.V², Sujai S3, Shivaprakash S.U ${ }^{4}$, Sreedhara D.K5
}

HOW TO CITE THIS ARTICLE:

Roshan Pais, Maruthi CV, Sujai S, Shivaprakash SU, Sreedhara DK. "Rare case of ulnar sesamoid fracture of the thumb: A case report". Journal of Evolution of Medical and Dental Sciences 2013; Vol2, Issue 31, August 5; Page: 5919-5922.

ABSTRACT: BACKGROUND: It's a rare injury, results from violent hyperextension, violent abduction or by direct injury. AIM: To diagnose, classify and treat a case of sesamoid fracture. MATERIAL AND METHOD: We present a case of an adult man, 37 years old, who suffered a violent abduction of the right thumb. The X-ray examination demonstrated a fracture of the ulnar sesamoid of the thumb. The fracture was treated by immobilization with thumb spica splint for two weeks. RESULTS: Follow up at three weeks, six weeks and eight months after the injury, shows total functional recovery of the thumb and healing of the fracture. CONCLUSION: Fracture of sesamoid bones of the thumb is a rare injury, not usually diagnosed, but it has good prognosis when treated properly.

KEY- WORDS: Sesamoid bone, Metacarpophalangeal joint, Thumb.

INTRODUCTION: From the eastern part of India, a plant called sesamum indicum which produces oval seeds, from which the term sesamoid is derived 1. Sesamoid bone fractures of metacarpophalangeal joint of thumb are very rare. Usual mechanism of injury is sudden violent hyperextension or sudden violent abduction, sometimes a direct injury ${ }^{2,3}$. To confirm the diagnosis digital $x$ - ray with antero-posterior and oblique views of thumb is necessary. The treatment is based on type of injury.

CASE REPORT: A 37 years old male patient arrived at the outpatient department complaining of pain at the base of the right thumb after a violent abduction injury during sudden application of horn while driving a car to avoid an accident. On examination, there was ecchymosis and oedema around the thumb and pain at the ulnar side of the palmar aspect of the metacarpophalangeal joint (Picture 1). Passive and active range of movements of interphalangeal and MCP joints were reduced with no neurovascular problem. The stability in the acute phase was assessed by local block for pain, the joint was stable. The antero-posterior and the oblique digital x-ray of the region demonstrated a transverse fracture of the ulnar sesamoid of the MCPJ of the thumb (Picture 2).

Patient was put on anti-inflammatory drugs for 5 days and thumb spica splint with metacarpophalangeal joint at $30^{\circ}$ flexion for three weeks. At three weeks patient was allowed to start range of movement at metacarpo-phalangeal joint and the interphalangeal joint, but not allowed to grip actively for another three weeks.

RESULTS: Three weeks after the injury the clinical examination of the patient demonstrated tenderness reduced and he was advised to start mobilization. The clinical examination six weeks after the injury demonstrated a full recovery of the function of the thumb. During eight months 


\section{CASE REPORT}

follow-up, no complications were reported and we noticed union of the fracture on the X-ray (picture 3). The patient is successfully employed as a software engineer.

DISCUSSION: The function of sesamoids at metacarpophalangeal joint of thumb related to stabilization and protection of flexor region of the joint 4. Metacarpophalangeal joint of thumb is stabilised by collateral ligaments, palmar plate. The lateral margin of palmar plate contains sesamoids where the fibrous tunnel for flexor pollicis longus tendon starts. Accessory collateral ligaments are inserted in to the lateral margin of the sesamoids. The tendon of adductor pollicis is inserted in to the ulnar sesamoid and flexor pollicis brevis to the radial sesamoid and then to the base of proximal phalanx ${ }^{5}$. Fracture of sesamoids results from sudden violent hyperextension 2, 4, 6 , or sudden abduction ${ }^{6}$ and sometimes by direct injury ${ }^{3}$. In our case the injury was the result of a sudden violent abduction of thumb during application of horn while driving a car to avoid accident. The fracture may be associated with rupture of palmar plate or rupture of accessory collateral ligaments or dislocation of thumb metacarpophalangeal joint. There are two types of sesamoid fractures depending on whether the palmar plate is injured or not. In Type I palmar plate is intact; patient maintains normal flexion posture of metacarpophalangeal joint and able to flex metacarpophalangeal joint and interphalangeal joint ${ }^{7}$. In Type II palmar plate is ruptured, patient's metacarpophalangeal joint assumes hyperextension posture and not able to flex the interphalangeal joint ${ }^{7}$. Our case is a type I injury as per this classification. Usual way of presentation is pain, swelling ecchymosis along the palmar aspect of metacarpophalangeal joint, examination reveals tenderness over the injured sesamoid bone and stability and type of injury is assessed by local block for pain. Radiological examination is done by taking radial and ulnar oblique views and of uninjured side preferably by digital $x$-ray, routine anteroposterior view using conventional x-ray imaging does not reveal the fracture ${ }^{8}$. Treatment for type I injuries is thumb cast or splint ${ }^{8,9}$. The thumb cast or splint is applied at 20 to 30 degree of flexion of metacarpophalangeal joint for 2 to 3 weeks $4,6,8$. Mobilization of metacarpophalangeal joint and interphalangeal joint started at this stage. Patient will gain back his full range of movements without pain by six weeks. Radiological examination is done at 6 weeks and 6 months to visualize healing signs at the fracture. In our case we performed radiological examination at eight months following the injury which showed complete union at fracture site. Type II injuries need surgical intervention by repairing the volar plate. If the patient is persistently complaining of pain even after several months of treatment, excision of sesamoid is considered 9,10 .

CONCLUSION: Sesamoid bone fractures of metacarpophalangeal joint of thumb are very rare injuries. The second most common mode of injury is sudden violent abduction of thumb. Type 1 injuries with palmar plate intact can be treated conservatively. Most of the cases will have good functional recovery and recession of pain with good prognosis.

\section{REFERENCES:}

1. Wood VE. The sesamoid bones of the hand and their pathology. J Hand Surg 1984; 9: 261264.

2. Ishizuki M, Nakagawa T, Ito S. Hyperextension injuries of the MP joint of the thumb. J Hand Surg 1994; 19: 361-367. 
3. Gibeault JD, Saba P, Hoenecke H, Graham A. The sesamoids of the metacarpophalangeal joint of the thumb: an anatomical and clinical study. J Hand Surg 1989; 14: 244-247.

4. Shaw M, Lyburn LD, Torreggiani WC, Watura R. Comminuted fracture of the ulnar sesamoid of the metacarpophalangeal joint of the thumb: an uncommon injury. J Emerg Med. 2003; 24: 437-439.

5. Gibeault JD, Saba P, Hoenecke H, Graham A. The sesamoids of the metacarpophalangeal joint of the thumb: An anatomical and clinical study. J Hand Surg Br. 1989; 14(2):244-247.

6. Van Der Lei B, Van Der Linden E, Mooyaart EL, Klasen HJ. Fracture of the thumb sesamoid bone: A report of three cases and a review of the English- language literature. J Trauma. 1995; 38: 836-840.

7. Patel MR, Peralman HS, Bassini L, Ravich S. Fractures of the sesamoid bones of the thumb. J Hand Surg 1990; 15:776- 781.

8. Dong PR, Seeger LL, Shapiro MS, Levere SM. Fractures of the sesamoid bones of the thumb. Am J Sports Med. 1995; 23: 336-339.

9. Hansen CA, Peterson TH. Fracture of the thumb sesamoid bones. J Hand Surg 1987; 12: 269270.

10. Dodenhoff RM. Fracture of the thumb sesamoid. Injury. 1996; 27: 213-214.

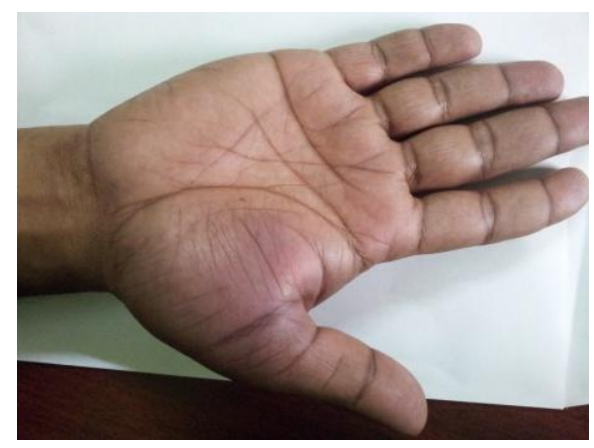

Initial clinical

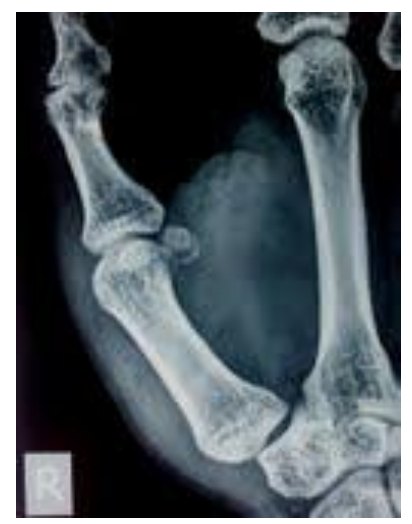

Initial ap 


\section{CASE REPORT}

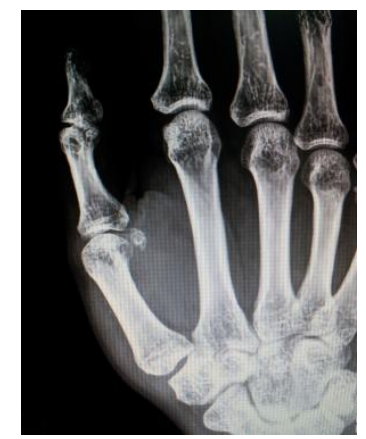

8 months ap

\section{AUTHORS:}

1. Roshan Pais

2. Maruthi C.V.

3. Sujai S.

4. Shivaprakash S.U.

5. Sreedhara D.K.

\section{PARTICULARS OF CONTRIBUTORS}

1. Assistant Professor, Department of Orthopaedics, MVJ Medical College and Research Hospital, Hoskote, Bangalore.

2. Assistant Professor, Department of Orthopaedics, MVJ Medical College and Research Hospital, Hoskote, Bangalore.

3. Assistant Professor, Department of Orthopaedics, MVJ Medical College and Research Hospital, Hoskote, Bangalore.
4. Assistant Professor, Department of Orthopaedics, MVJ Medical College and Research Hospital, Hoskote, Bangalore.

5. Associate Professor, Department of Orthopaedics, MVJ Medical College and Research Hospital, Hoskote, Bangalore.

\section{NAME ADRRESS EMAIL ID OF THE CORRESPONDING AUTHOR:}

Dr. Maruthi C.V., $6^{\text {th }}$ Cross, Opp. To APMC yard, Sir M.V. Layout, M.G. Road, Chickballapur - 562101.

Email - cvmaruthi@sify.com

Date of Submission: 30/07/2013. Date of Peer Review: 30/07/2013. Date of Acceptance: 01/08/2013. Date of Publishing: 05/08/2013. 